\title{
Higher Order derivatives of bulk modulus of materials at infinite pressure
}

\begin{tabular}{|r|l|}
\hline Journal: & Canadian Journal of Physics \\
\hline Manuscript ID & cjp-2015-0699.R2 \\
\hline Manuscript Type: & Article \\
\hline Date Submitted by the Author: & 02-Apr-2016 \\
\hline Complete List of Authors: & DWIVEDI, ASHUTOSH; Institute of Basic Sciences, Department Of Physics \\
\hline Keyword: & $\begin{array}{l}\text { Bulk modulus, pressure derivatives, third-order Grüneisen parameter, } \\
\text { infinite pressure behaviour, thermoelastic properties of materials at } \\
\text { extreme compression }\end{array}$ \\
\hline & \multicolumn{2}{|l}{} \\
\hline
\end{tabular}

SCHOLARONE ${ }^{\text {IM }}$

Manuscripts 


\title{
Revised Manuscript ID cjp-2015-0699
}

\author{
A. Dwivedi* \\ Department of Physics, Institute of Basic Sciences, Khandari Campus, \\ Agra - 282 002, Uttar Pradesh, INDIA \\ *E-mail : adwd40@gmail.com
}

\begin{abstract}
Pressure derivatives of bulk modulus of materials at infinite pressure or extreme compression have been studied using some basic principles of calculus. Expressions for higher order pressure derivatives at infinite pressure are obtained which are found to have the status of identities. A generalized formula is derived for the $\mathrm{n}$-th order pressure derivative of bulk modulus in terms of the third-order Grüneisen parameter at infinite pressure.
\end{abstract}

Keywords : Bulk modulus, pressure derivatives, third-order Grüneisen parameter, infinite pressure behaviour.

PACS : 64.70. Dv, 62.50. + p, 65.40. - b

\section{INTRODUCTION}

All equations of state, which are physically acceptable, must satisfy the constraint $[1,2]$ that pressure $\mathrm{P}$ tends to infinity for materials at extreme compression (volume $\mathrm{V}$ tends to zero). This is the fundamental constraint which leads to some very important results for the development of equation of state [3-7] and thermoelastic properties of materials at extreme compression [8-12]. Any equation of state or thermodynamic formulation is valid only if it satisfies the boundary conditions both at $\mathrm{P}=0$ (atmospheric pressure) and in the limit of infinite pressure. No material can exist at infinite pressure, but the extrapolated values of parameters in the limit of extreme compression have been found to be very useful [13-16]. The extrapolation procedure is based on the assumption that the material does not exhibit any phase transition, but remains in the same phase when compressed down to the extreme limit $\mathrm{V} \rightarrow 0$. The extrapolated values of parameters at infinite pressure are equally important as the parameters at atmospheric pressure.

In order to derive thermodynamic relationships and identities at infinite pressure, we make use of some basic principles of calculus $[17,18]$ which are written as follows. If $\mathrm{y}$ is a function of $\mathrm{x}$ such that $\mathrm{y}$ remains positive finite at $\mathrm{x}$ tends to zero, then

$$
\left(\frac{d \ln y}{d \ln x}\right)_{x \rightarrow 0}=0
$$

If $\mathrm{y}$ becomes zero at $\mathrm{x}$ tends to zero, then 


$$
\left(\frac{d \ln y}{d \ln x}\right)_{x \rightarrow 0}=\text { positive finite }
$$

If $\mathrm{y}$ tends to infinity at $\mathrm{x}$ tends to zero, then

$$
\left(\frac{d \ln y}{d \ln x}\right)_{x \rightarrow 0}=\text { negative finite }
$$

We use Eqs. (1) to (3) to investigate the infinite pressure behaviour of materials. Expressions for pressure derivatives of bulk modulus are obtained at infinite pressure which have the status of identities.

\section{INFINITE PRESSURE BEHAVIOUR}

$\mathrm{P}$ is a function of $\mathrm{V}$ such that $\mathrm{P}$ increases continuously with the decreasing $\mathrm{V}$. At extreme compression $(\mathrm{V} \rightarrow 0)$, $\mathrm{P}$ becomes infinitely large, then according to Eq. (3) we can write

$$
\left(\frac{\mathrm{d} \ln \mathrm{P}}{\mathrm{d} \ln \mathrm{V}}\right)_{\mathrm{V} \rightarrow 0}=\text { negative finite }
$$

Since

$$
\frac{\mathrm{d} \ln \mathrm{P}}{\mathrm{d} \ln \mathrm{V}}=-\frac{\mathrm{K}}{\mathrm{P}}
$$

where $\mathrm{K}$ is bulk modulus

$$
K=-V \frac{d P}{d V}
$$

Equations (4) and (5) yield

$$
\left(\frac{\mathrm{K}}{\mathrm{P}}\right)_{\infty}=\text { positive finite }
$$

Now taking $\mathrm{y}=\mathrm{K} / \mathrm{P}$ and $\mathrm{x}=\mathrm{V}$ in Eq. (1), we have

$$
\left[\frac{\mathrm{d} \ln (\mathrm{K} / \mathrm{P})}{\mathrm{d} \ln \mathrm{V}}\right]_{\mathrm{V} \rightarrow 0}=0
$$

because $\mathrm{K} / \mathrm{P}$ is positive finite (Eq. 7). On solving Eq. (8), we get

$$
\left(1-\mathrm{K}^{\prime} \mathrm{P} / \mathrm{K}\right)_{\infty}=0
$$

Equation (9) yields 


$$
\mathrm{K}_{\infty}^{\prime}=\left(\frac{\mathrm{K}}{\mathrm{P}}\right)_{\infty}
$$

Equation (10) has the status of an identity $[1,2,19]$. In view of Eq. (7), it is revealed from Eq. (10) that $\mathrm{K}_{\infty}^{\prime}$, the pressure derivative of bulk modulus, $\mathrm{dK} / \mathrm{dP}$, at infinite pressure remains positive finite. The subscript $\infty$ has been used for representing the values at infinite pressure or extreme compression. Eq. (7) also reveals that at $\mathrm{P} \rightarrow \infty$, the bulk modulus $\mathrm{K} \rightarrow \infty$, but the ratio $\mathrm{K} / \mathrm{P}$ remains positive finite. According to Eq. (3), we then write

$\left(\frac{\mathrm{d} \ln \mathrm{K}}{\mathrm{d} \ln \mathrm{V}}\right)_{\mathrm{V} \rightarrow 0}=$ negative finite

We have

$$
\mathrm{K}^{\prime}=\frac{\mathrm{dK}}{\mathrm{dP}}=-\left(\frac{\mathrm{d} \ln \mathrm{K}}{\mathrm{d} \ln \mathrm{V}}\right)
$$

Equations (11) and (12) give

$\mathrm{K}_{\infty}^{\prime}=$ positive finite

Now, the second order pressure derivative of bulk modulus

$\frac{\mathrm{d}^{2} \mathrm{~K}}{\mathrm{dP}^{2}}=\mathrm{K}^{\prime \prime}=\frac{\mathrm{dK}^{\prime}}{\mathrm{dP}}=-\frac{\mathrm{V}}{\mathrm{K}} \frac{\mathrm{dK}}{\mathrm{dV}}$

Equation (14) gives

$$
\mathrm{KK}^{\prime \prime}=-\mathrm{K}^{\prime}\left(\frac{\mathrm{d} \ln \mathrm{K}^{\prime}}{\mathrm{d} \ln \mathrm{V}}\right)
$$

At infinite pressure, $\mathrm{K}^{\prime} \rightarrow \mathrm{K}_{\infty}^{\prime}$ which remains positive finite, then according to Eq. (1) we have

$\left(\frac{\mathrm{d} \ln \mathrm{K}^{\prime}}{\mathrm{d} \ln \mathrm{V}}\right)_{\mathrm{V} \rightarrow 0}=0$

Equations (15) and (16) yield

$\left(\mathrm{KK}^{\prime \prime}\right)_{\infty}=0$

According to Eq. (2) we must have 
$\left(\frac{\mathrm{d} \ln \mathrm{KK}}{\mathrm{d} \ln \mathrm{V}}\right)_{\mathrm{V} \rightarrow 0}=$ positive finite

The left hand side of equation (18) can be written as

$\left(\frac{\mathrm{d} \ln \mathrm{KK}^{\prime \prime}}{\mathrm{d} \ln \mathrm{V}}\right)_{\mathrm{V} \rightarrow 0}=-\mathrm{K}_{\infty}^{\prime}-\left(\frac{\mathrm{K}^{2} \mathrm{~K}^{\prime \prime \prime}}{\mathrm{KK}^{\prime \prime}}\right)_{\infty}$

where $\mathrm{K}^{\prime \prime}=\mathrm{d}^{3} \mathrm{~K} / \mathrm{dP}^{3}$. It has been found $[17,18,20]$ that the right hand side of Eq. (19) is positive finite equal to the third order Grüneisen parameter at infinite pressure

$\lambda_{\infty}=-\mathrm{K}_{\infty}^{\prime}-\left(\frac{\mathrm{K}^{2} \mathrm{~K}^{\prime \prime \prime}}{\mathrm{KK}^{\prime \prime}}\right)_{\infty}$

There exists another simple principle of calculus. If the ratio of two functions of a common variable (such as volume or pressure) becomes indeterminate (zero divided by zero, or infinity divided by infinity) at a particular value of the variable, then this ratio of two functions becomes equal to the ratio of the differential derivatives of these two functions at that point. The last term in Eq. (20) is finite. Since (KK") $)_{\infty}$ is zero (Eq. 17), therefore $\left(\mathrm{K}^{2} \mathrm{~K}^{\prime \prime \prime}\right)_{\infty}$ also becomes zero. We can write

$$
\left(\frac{\mathrm{K}^{2} \mathrm{~K}^{\prime \prime \prime}}{\mathrm{KK} \mathrm{K}^{\prime \prime}}\right)_{\infty}=\left(\frac{2 \mathrm{~K} \mathrm{~K}^{\prime} \mathrm{K}^{\prime \prime \prime}+\mathrm{K}^{2} \mathrm{~K}^{\mathrm{IV}}}{\mathrm{K}^{\prime} \mathrm{K}^{\prime \prime}+\mathrm{K} \mathrm{K}^{\prime \prime}}\right)_{\infty}
$$

Rearranging the terms in Eq. (21), we get

$$
\left(\frac{\mathrm{K}^{3} \mathrm{~K}^{\mathrm{IV}}}{\mathrm{K}^{2} \mathrm{~K}^{\prime \prime \prime}}\right)_{\infty}=-\mathrm{K}_{\infty}^{\prime}+\left(\frac{\mathrm{K}^{2} \mathrm{~K}^{\prime \prime \prime}}{\mathrm{KK}^{\prime \prime}}\right)_{\infty}
$$

where $\mathrm{K}^{\mathrm{IV}}=\mathrm{d}^{4} \mathrm{~K} / \mathrm{dP}^{4}$. The next order pressure derivative can be obtained by writing

$$
\left(\frac{\mathrm{K}^{3} \mathrm{~K}^{\mathrm{IV}}}{\mathrm{K}^{2} \mathrm{~K}^{\prime \prime \prime}}\right)_{\infty}=\left(\frac{3 \mathrm{~K}^{2} \mathrm{~K}^{\prime} \mathrm{K}^{\mathrm{IV}}+\mathrm{K}^{3} \mathrm{~K}^{\mathrm{V}}}{2 \mathrm{KK}^{\prime} \mathrm{K}^{\prime \prime}+\mathrm{K}^{2} \mathrm{~K}^{\mathrm{IV}}}\right)_{\infty}
$$

On solving Eq. (23), we find the following expression

$$
\left(\frac{\mathrm{K}^{4} \mathrm{~K}^{\mathrm{V}}}{\mathrm{K}^{3} \mathrm{~K}^{\mathrm{IV}}}\right)_{\infty}=-\mathrm{K}_{\infty}^{\prime}+\left(\frac{\mathrm{K}^{3} \mathrm{~K}^{\mathrm{IV}}}{\mathrm{K}^{2} \mathrm{~K}^{\prime \prime}}\right)_{\infty}
$$

Equations (22) and (24) then yield

$$
\left(\frac{\mathrm{K}^{4} \mathrm{~K}^{\mathrm{V}}}{\mathrm{K}^{3} \mathrm{~K}^{\mathrm{IV}}}\right)_{\infty}=-2 \mathrm{~K}_{\infty}^{\prime}+\left(\frac{\mathrm{K}^{2} \mathrm{~K}^{\prime \prime \prime}}{\mathrm{KK}^{\prime \prime}}\right)_{\infty}
$$


where $\mathrm{K}^{\mathrm{V}}=\mathrm{d}^{5} \mathrm{~K} / \mathrm{dP}^{5}$.

We thus obtain the following generalized expression for the higher pressure derivatives of bulk modulus at infinite pressure

$$
\left[\frac{K^{n}\left(d^{n+1} K / d P^{n+1}\right)}{K^{n-1}\left(d^{n} K / d P^{n}\right)}\right]_{\infty}=-(n-2) K_{\infty}^{\prime}+\left(\frac{K^{2} K^{\prime \prime \prime}}{K K^{\prime \prime}}\right)_{\infty}=-(n-1) K_{\infty}^{\prime}-\lambda_{\infty}
$$

where $\mathrm{n}$ is a positive integer such that $\mathrm{n} \geq 2$. The third order Grüneisen parameter $\lambda_{\infty}$ is given by Eq. (20) for the materials at extreme compression [17, 18]. It should be mentioned here that $\left(1-K^{\prime} P / K\right)_{\infty}$ is zero (Eq. 9), and therefore according to Eq. (2) we can write

$$
\left[\frac{\mathrm{d} \ln \left(1-\mathrm{K}^{\prime} \mathrm{P} / \mathrm{K}\right)}{\mathrm{d} \ln \mathrm{V}}\right]_{\infty}=\text { positive finite }
$$

Eq. (27) reveals that $[17,18]$

$$
\left[\frac{\mathrm{KK}^{\prime \prime}}{1-\mathrm{K}^{\prime} \mathrm{P} / \mathrm{K}}\right]_{\infty}=\text { finite }
$$

Numerator and denominator of the left of Eq. (28), both tend to zero at infinite pressure but their ratio remains finite. Using the calculus of indeterminates we write

$$
\left[\frac{\mathrm{KK}^{\prime \prime}}{\left(1-\mathrm{K}^{\prime} \mathrm{P} / \mathrm{K}\right)}\right]_{\infty}=-\frac{\mathrm{K}_{\infty}^{\prime}+\left(\frac{\mathrm{K}^{2} \mathrm{~K}^{\prime \prime \prime}}{\mathrm{KK}^{\prime \prime}}\right)}{\mathrm{K}_{\infty}^{\prime}\left[\frac{\left(1-\mathrm{K}^{\prime} \mathrm{P} / \mathrm{K}\right)}{\mathrm{K} \mathrm{K}^{\prime \prime}}\right]+\frac{1}{\mathrm{~K}_{\infty}^{\prime}}}
$$

On solving Eq. (29), we get $[17,18]$

$$
\left(\frac{\mathrm{K}^{2} \mathrm{~K}^{\prime \prime \prime}}{\mathrm{KK}^{\prime \prime}}\right)_{\infty}=-2 \mathrm{~K}_{\infty}^{\prime}-\frac{1}{\mathrm{~K}_{\infty}^{\prime}}\left(\frac{\mathrm{KK}^{\prime \prime}}{1-\mathrm{K}^{\prime} \mathrm{P} / \mathrm{K}}\right)_{\infty}
$$

Equations (20) and (30) yield

$$
\lambda_{\infty}=\mathrm{K}_{\infty}^{\prime}+\frac{1}{\mathrm{~K}_{\infty}^{\prime}}\left(\frac{\mathrm{KK}^{\prime \prime}}{1-\mathrm{K}^{\prime} \mathrm{P} / \mathrm{K}}\right)_{\infty}
$$

Equations (30) and (31) can be used to determine the last terms in Eq. (26). Thus the higher order derivatives of bulk modulus at infinite pressure can be determined with the help of first and second derivatives of bulk modulus.

It is pertinent to mention here that the expressions obtained in the present study are based on the fundamental principles of calculus and are therefore independent of any 
specific forms of equation of state. An attempt was made earlier [21] to determine pressure derivatives of bulk modulus using different forms of equation of state due to Birch [22], Poirier [23], Vinet [24], Keane [25] and Stacey [26]. The expressions thus obtained were found to depend on the parameters of the equations of state used. On the other hand, the higher order derivatives of bulk modulus reported in the present work are not based on any specific form of equation of state.

\section{CONCLUSIONS}

The theory of materials at infinite pressure originally due to Stacey $[1,2]$ and further developed by Shanker et al $[17,18]$ has been extended in the present study to determine the $\mathrm{n}$-th order pressure derivatives of bulk modulus at extreme compression. Using some basic principles of calculus it has been found that the higher order pressure derivatives of bulk modulus can be determined only with the help of first and second pressure derivatives of bulk modulus at infinite pressure. The most important parameters are $K_{\infty}^{\prime}$ and $\lambda_{\infty}$ which determine the pressure derivatives of bulk modulus up to $\mathrm{n}$-th order at infinite pressure using the generalized formula (Eq. 26) derived in the present study. It should be emphasized that the pressure derivatives of bulk modulus play the central role in determining thermoelastic properties and equations of state of materials [27-31].

\section{ACKNOWLEDGEMENT}

Author is thankful to Professor J. Shanker, Agra, India for his valuable guidance and helpful suggestions.

\section{References}

[1] F.D. Stacey, P.M. Davis, Phys. Earth Planet Inter. 142, 137 (2004).

[2] F.D. Stacey, Prog. Phys. 68, 341 (2005).

[3] K. Sushil, K. Arunesh, P.K. Singh, B.S. Sharma, Physica B 352, 134 (2004).

[4] S.S. Kushwah, H.C. Shrivastava, K.S. Singh, Physica B 388, 20 (2007).

[5] H.C. Shrivastava, Physica B 404, 251 (2009).

[6] S.S. Kushwah, N.K. Bhardwaj, J. Phys. Chem. Solids 70, 700 (2009).

[7] P.K. Vidyarthi, B.P. Singh, Physica B 410, 259 (2013).

[8] J. Shanker, B.P. Singh, K. Jitendra, Condens. Matter Phys. 12, 205 (2009).

[9] S.K. Srivastava, Solid State Commun. 151, 1472 (2011).

[10] S.S. Kushwah, M.P. Sharma, Y.S. Tomar, Solid State Sciences 13, 1162 (2011).

[11] K.S. Singh, Physica B 407, 668 (2012).

[12] A. Vijay, High Temperatures - High Pressures 43, 47 (2014)

[13] S.S. Kushwah, M.P. Sharma, Solid State Commun. 152, 414 (2012).

[14] S.S. Kushwah, Y.S. Tomar, M.P. Sharma, High Temperatures - High Pressures 41, 309 (2012).

[15] S.S. Kushwah, Y.S. Tomar, A.K. Upadhyay, J. Phys. Chem. Solids 74, 1143 (2013).

[16] S.S. Kushwah, A.K. Upadhyay, M.P. Sharma, High Temperatures - High Pressures, 44, 59 (2014).

[17] J. Shanker, P. Dualri, P.K. Singh, Physica B 404, 4083 (2009).

[18] J. Shanker, K. Sunil, B.S. Sharma, Physica B 407, 2082 (2012). 
[19] L. Knopoff, J. Geophysics. Res. 68, 2929 (1963).

[20] J. Shanker, B.P. Singh, Physica B 370, 78 (2005).

[21] P.K. Singh, A. Dwivedi, Indian J. Pure Appl. Phys. 50, 734 (2012).

[22] F, Birch, J. Geophys. Res. 91, 4949 (1986).

[23] J.P. Poirier, A. Tarantola, Phys. Earth Planet, Inter. 109, 1 (1998)

[24] P. Vinet, H.J. Rose, J. Ferrante, R.J. Smith, J. Phys. Condens. Matter 1, 1941 (1987).

[25] A. Keane, Aust, J. Phys. 7, 323 (1954).

[26] F.D. Stacey, Geophys. J. Int. 143, 621 (2000).

[27] O.L. Anderson, Equation of state for geophysics and ceramic sciences. Oxford University Press, New York, 1995.

[28] F.D. Stacey, Phys, Earth Planet Inter, 89, 219 (1995).

[29] S.K. Sharma, B.K. Sharma, Physica B 405, 3145 (2010).

[30] S.S. Kushwah, N.K. Bhardwaj, Int. J. Mod. Phys. B, 24, 1187 (2010).

[31] S. Kumar, S.K. Sharma, O.P. Pandey, High Temperatures - High Pressures 44, 339 (2015). 